\title{
Esophageal Squamous Cell Carcinoma by AJCC v8 Stage
}

National Cancer Institute

\section{Source}

National Cancer Institute. Esophageal Squamous Cell Carcinoma by A/CC v8 Stage. NCI Thesaurus. Code C133443.

A term that refers to the staging of esophageal squamous cell carcinoma according to the American Joint Committee on Cancer, 8th edition. 